\title{
Communication \\ Carbon Nanotube-Based Thermoelectric Modules Enhanced by ZnO Nanowires
}

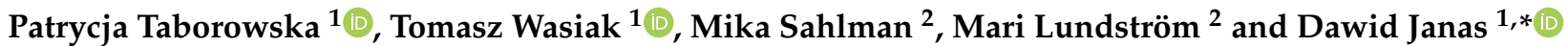 \\ 1 Department of Organic Chemistry, Bioorganic Chemistry and Biotechnology, Silesian University of \\ Technology, B. Krzywoustego 4, 44-100 Gliwice, Poland; patrycja.taborowska@polsl.pl (P.T.); \\ tomasz.wasiak@polsl.pl (T.W.) \\ 2 Hydrometallurgy and Corrosion, Department of Chemical and Metallurgical Engineering (CMET), \\ School of Chemical Engineering, Aalto University, P.O. Box 16200, FI-00076 Aalto, Finland; \\ mika.sahlman@aalto.fi (M.S.); mari.lundstrom@aalto.fi (M.L.) \\ * Correspondence: dawid.janas@polsl.pl; Tel.: +48-32-237-10-82
}

check for updates

Citation: Taborowska, P.; Wasiak, T.; Sahlman, M.; Lundström, M.; Janas,

D. Carbon Nanotube-Based

Thermoelectric Modules Enhanced by ZnO Nanowires. Materials 2022, 15, 1924. https://doi.org/10.3390/ ma15051924

Academic Editor: Nuno Ferreira

Received: 8 February 2022

Accepted: 3 March 2022

Published: 4 March 2022

Publisher's Note: MDPI stays neutral with regard to jurisdictional claims in published maps and institutional affiliations.

Copyright: (c) 2022 by the authors. Licensee MDPI, Basel, Switzerland. This article is an open access article distributed under the terms and conditions of the Creative Commons Attribution (CC BY) license (https:// creativecommons.org/licenses/by/ $4.0 /)$.

\begin{abstract}
Carbon nanotubes (CNTs) have a wide range of unique properties, which have kept them at the forefront of research in recent decades. Due to their electrical and thermal characteristics, they are often evaluated as key components of thermogenerators. One can create thermogenerators exclusively from CNTs, without any metal counterpart, by properly selecting dopants to obtain nand p-doped CNTs. However, the performance of CNT thermogenerators remains insufficient to reach wide commercial implementation. This study shows that molecular doping and the inclusion of $\mathrm{ZnO}$ nanowires (NWs) can greatly increase their application potential. Moreover, prototype modules, based on single-walled CNTs (SWCNTs), ZnO NWs, polyethyleneimine, and triazole, reveal notable capabilities for generating electrical energy, while ensuring fully scalable performance. Upon doping and the addition of $\mathrm{ZnO}$ nanowires, the electrical conductivity of pure SWCNTs $(211 \mathrm{~S} / \mathrm{cm})$ was increased by a factor of three. Moreover, the proposed strategy enhanced the Power Factor values from 18.99 (unmodified SWCNTs) to 34.9 and $42.91 \mu \mathrm{W} / \mathrm{m} \cdot \mathrm{K}^{2}$ for CNTs triazole and polyethyleneimine + ZnO NWs inclusion, respectively.
\end{abstract}

Keywords: carbon nanotubes; $\mathrm{ZnO}$ nanowires; thermoelectric properties

\section{Introduction}

The progressing electrification of our daily lives puts more and more pressure on the electric grid [1-3]. A modern house contains numerous appliances, each of which requires electrical energy. Furthermore, various gadgets, such as smartphones, smartwatches, etc., used by us also require such resources to operate. Therefore, more power plants are needed to fulfil the future demand. However, electrical energy generation is currently inefficient, and more than half of the energy is lost in the process as waste heat [4]. It is, therefore, highly reasonable to address the challenge of the low overall yield of the current approach.

New types of materials, which emerged at the turn of the XX and XXI centuries, may solve this problem. In particular, carbon nanostructures, such as carbon nanotubes (CNTs) [5] have highly useful characteristics, making them attractive in this area. They may provide remarkable electrical [6,7] and thermal [8,9] properties, and even outperform copper, in terms of current carrying capacity [10,11] and thermal conductivity [12]. Among the most important attributes of CNTs is the capability to induce thermoelectric voltage when subjected to a temperature gradient $[13,14]$. The thermoelectric capability of CNTs is quantified by a parameter referred to as the Seebeck coefficient, which quantifies the amount of electrical charge generated per unit temperature.

As highlighted in a comprehensive review on the topic by Blackburn and colleagues [15], CNTs are well suited for harvesting low-grade heat in the 300-400 K temperature regime. They can provide an alternative to typical inorganic thermoelectric materials, designed for 
operation above $600 \mathrm{~K}$ (e.g., $\left.\mathrm{Bi}_{2} \mathrm{Te}_{3}, \mathrm{PbTe}\right)$, which are toxic, rigid and based on metals of limited abundance [16-18]. In contrast, thermogenerators based on CNTs are flexible, and the constituting CNTs can be made from a myriad of carbon-containing renewable chemical compounds [19]. Furthermore, they have highly tunable characteristics [20,21], which can be tailored by exercising an appropriate modification strategy. One of the key attributes of CNTs is that they are amphoteric, which means that they can be both p- or n-doped [22]. Consequently, p-type and n-type thermoelements, constituting thermoelectric modules, can be made using CNTs. CNTs are naturally p-doped in the ambient environment $[23,24]$, so researchers' current focus is on finding chemical compounds or materials that can make high-performance n-type thermoelements from CNTs. Various electron-rich molecular dopants, such as 1,3-Bis (diphenyl-phosphino) propane, poly (4-vinylpyridine) or Tetronic 1107, have been tested [22]. Chemical compounds, however, may be prone to desorption or degradation (especially at high temperature).

In this work, we investigate the possibility of using $\mathrm{ZnO}$ nanowires (NWs), having n-type characteristics [25], to enhance the thermoelectric performance of modules based on single-walled CNTs (SWCNTs). It is essential that they are not made of critical raw materials like those mentioned above. Pure SWCNTs were n- and p-doped and the effect of $\mathrm{ZnO} N W$ addition on the values of electrical/thermal conductivity, Seebeck coefficient, Power Factor, and Figure of Merit (zT) was analyzed. The study demonstrates that the addition of ZnO NWs is highly beneficial for the SWCNT-based thermoelectric modules.

\section{Materials and Methods}

\subsection{Chemical Compounds}

SWCNTs (Tuball ${ }^{\mathrm{TM}}$, OCSiAl, Leudelange, Luxemburg), zinc nitrate hexahydrate (Acros Organics, Geel, Belgium, 98\%), sodium hydroxide (Chempur, Piekary Slaskie, Poland, pure p.a.), sodium dodecyl sulfate (Sigma-Aldrich, Saint-Louis, MO, USA; 92.5-100.5\%), acetone (Avantor, Gliwice, Poland), toluene (Avantor, Gliwice, Poland), were obtained from the indicated vendors.

\subsection{Synthesis of $\mathrm{ZnO} N W s$}

First, $20 \mathrm{~mL}$ of $1 \mathrm{M} \mathrm{Zn}\left(\mathrm{NO}_{3}\right)_{2}$ water solution was poured into a $(250 \mathrm{~mL})$ round-bottom flask. The solution was diluted with $45 \mathrm{~mL}$ of distilled water and cooled down to $1^{\circ} \mathrm{C}$ in an ice bath with salt. The mixture was continuously stirred, and then $30 \mathrm{~mL}$ of $4 \mathrm{M} \mathrm{NaOH}$ was added dropwise afterward. At first, a white precipitate could be observed, which slowly dissolved with each drop of the base. Then $5 \mathrm{~mL}$ of $0.2 \mathrm{M}$ SDS solution was injected. The solution was stirred at room temperature for $1.5 \mathrm{~h}$ to obtain a white precipitate. Next, the flask was equipped with a condenser and placed in an oil bath heated up to $85{ }^{\circ} \mathrm{C}$. The growth of ZnO NWs was conducted without stirring. The obtained product was filtered off, washed with copious amounts of distilled water, and dried in air.

\subsection{Assembly of Doped SWCNT Films}

SWCNTs were transformed into thin free-standing films by adapting a method reported by us previously [26]. The process is summarized in Figure 1. To make n- and p-doped SWCNT films, polyethyleneimine (PEI) or triazole were introduced to $80 \mathrm{~mL}$ of acetone/toluene mixture $(1: 1, w / w)$ at the concentration of $0.1 \mathrm{M}$, respectively. Then, SWCNTs and ZnO NWs (in the case of n-doping solution) were added in the amounts indicated in Table 1. Then, the mixture was sonicated over an ice bath until obtaining a uniform dispersion (UP200St sonicator, Hielscher, Teltow, Germany). Subsequently, it was filtered under reduced pressure onto membranes from Teflon (pore size: $0.45 \mu \mathrm{m}$, diameter: $47 \mathrm{~mm}$; Fisherbrand, Ottawa, ON, Canada) using a Büchner funnel and a vacuum flask. The films formed on the filters were then kept in a desiccator overnight to facilitate the evaporation of the solvents. Once dried, they were delaminated from the support due to their low adhesion to PTFE. Thus, $2 \mathrm{~mm} \times 40 \mathrm{~mm}$ specimens (thickness $100 \mu \mathrm{m}$ ) were produced from the films for analysis. 


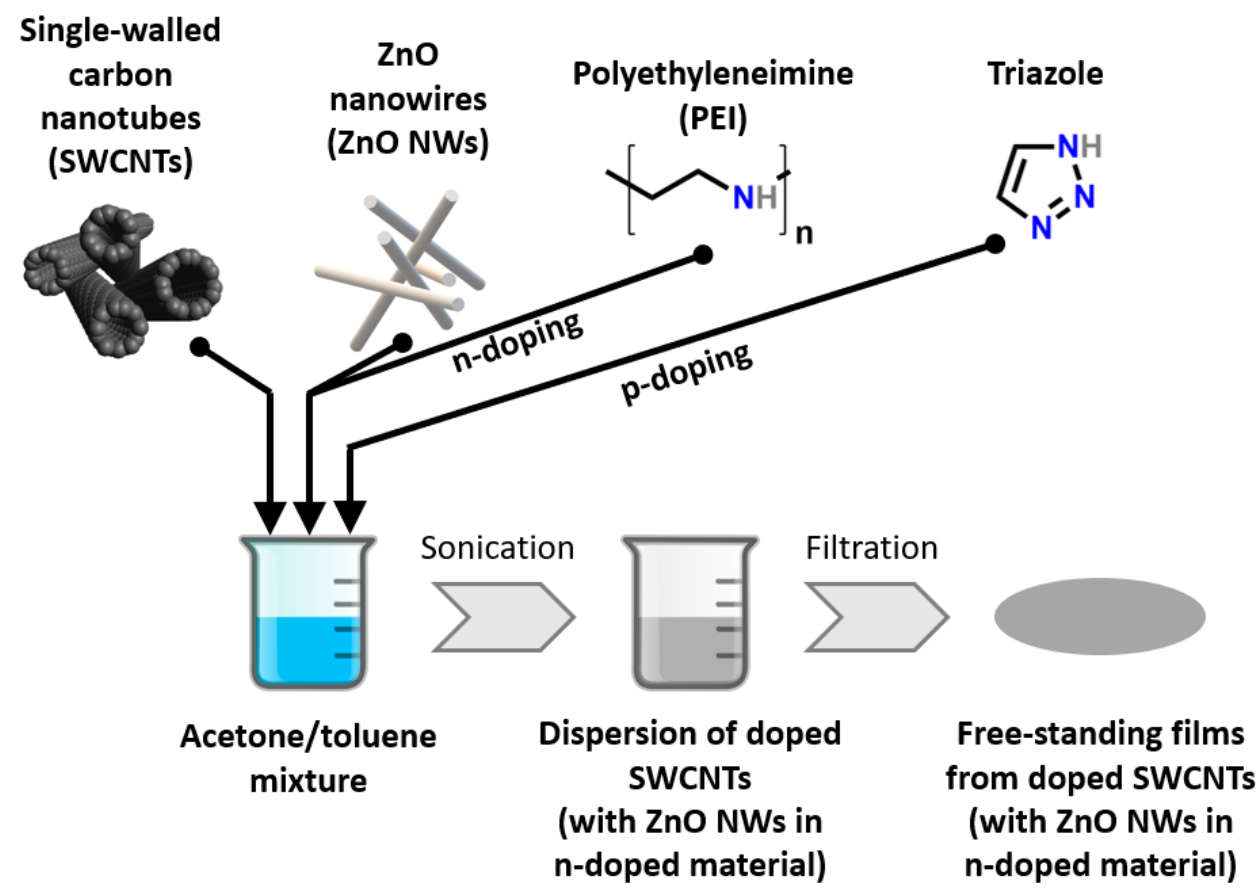

Figure 1. Assembly and doping of SWCNT films for thermoelectric applications.

Table 1. Composition of the mixtures used to form SWCNT films in this study.

\begin{tabular}{cccccc}
\hline Sample & $\begin{array}{c}\text { SWCNTs } \\
{[\mathbf{m g}]}\end{array}$ & $\begin{array}{c}\text { PEI } \\
{[\mathbf{M}]}\end{array}$ & $\begin{array}{c}\text { Triazole } \\
{[\mathbf{M}]}\end{array}$ & $\begin{array}{c}\text { ZnO } \\
{[\mathbf{m g}]}\end{array}$ & $\begin{array}{c}\text { Solvent } \\
\text { Mixture [mL] }\end{array}$ \\
\hline $\begin{array}{c}\text { Pure SWCNT film } \\
\text { n-doped SWCNT film }\end{array}$ & 150.0 & - & - & - & 80 \\
$\begin{array}{c}\text { n-doped SWCNT film filled } \\
\text { with ZnO NWs (5 wt\%) }\end{array}$ & 150.0 & 0.1 & - & - & 80 \\
$\begin{array}{c}\text { n-doped SWCNT film filled } \\
\text { with ZnO NWs (10 wt\%) }\end{array}$ & 142.5 & 0.1 & - & 7.5 & 80 \\
$\begin{array}{c}\text { n-doped SWCNT film filled } \\
\text { with ZnO NWs (15 wt\%) } \\
\text { p-doped SWCNT film }\end{array}$ & 127.5 & 0.1 & - & 22.5 & 80 \\
\hline
\end{tabular}

\subsection{Characterization}

Raman spectroscopy was employed to investigate the possibility of electronic and structural differences between the specimens. The inVia Renishaw Raman microscope (Renishaw, Wotton-under-Edge, UK) with a laser wavelength of $\lambda=514 \mathrm{~nm}$ acquired data from 10 to $3200 \mathrm{~cm}^{-1}$. Spectra were obtained at several sample areas using extended acquisition time to ensure statistical significance and high signal-to-noise ratio, respectively.

X-ray diffraction (XRD, Rigaku D-max 2500, Tokyo, Japan) was used to study the crystallinity of ZnO NWs. A CuK $\alpha$ monochromatic X-ray source was engaged to collect the data for $2 \theta$ between $30^{\circ}$ and $80^{\circ}$. A $0.03^{\circ} 2 \theta$ step size was set to resolve the recorded patterns properly.

Scanning Electron Microscope (SEM; Quanta 250 FEG, Hillsboro, OR, USA) was employed to investigate the microstructure of the material. Image acquisition was conducted at the acceleration voltage of $10 \mathrm{kV}$. The samples were not sputtered.

A custom made 4-probe setup was used to evaluate electrical conductivity of the material (Keithley 2450 SourceMeter, Cleveland, OH, USA). The specimens were attached to a sample holder using Ag conductive paint to avoid contact resistance. Resistance of the samples was then measured by supplying a $100 \mathrm{~mA}$ current, which did not elevate the temperature of the samples. The recorded values of resistance were recalculated into 
conductivity by considering the sample dimensions. Thickness was established using a micrometer screw gauge (Electronic Universal IP54, Linear Tools, Dunstable, UK).

A steady-state method with infrared thermography [27-29] was implemented to obtain thermal conductivity values analogously as in our previous work [30]. In brief, the temperature profile of the sample was analyzed in an evacuated chamber using a thermal camera (FLIR ETS 320, Wilsonville, OR, USA). The recorded data were then modeled using the following equation

$$
\kappa=\frac{U \cdot I \cdot 0.5 L}{4 \cdot w \cdot t \cdot\left(T_{m}-T_{0}\right)}
$$

where $\kappa$ is thermal conductivity, $U$ is voltage, $I$ is current, $L, w$, and $t$ are length, width, and thickness of the sample, respectively. $T_{0}$ and $T_{m}$ are temperatures of the sample ends and middle part, respectively.

Seebeck coefficient was determined from room temperature to $110^{\circ} \mathrm{C}$ (SeebCam, LBR, Lublin, Poland) at the temperature gradient of $5{ }^{\circ} \mathrm{C}$ between the sample ends. The values of electric potential were registered under these conditions (the material was studied in an evacuated chamber to eliminate the influence of convection). The performance of modules containing 5, 10, and $15 \mathrm{n}$-p pairs was analyzed by heating one side of the module with a hot plate (temperature was verified with a Type K thermocouple). Open Circuit Voltage was measured across the above-mentioned temperature range with a source meter (Keithley 2450 SourceMeter, Cleveland, OH, USA) to confirm the utility of the developed solution.

The values of Power Factor $(P F)$ and Figure of Merit $(z T)$ were calculated using the following formula.

$$
\begin{gathered}
\text { PF }=\sigma \cdot S^{2} \\
z T=\frac{\sigma \cdot S^{2}}{\kappa} T
\end{gathered}
$$

where $\sigma$ is electrical conductivity, and $S$ is Seebeck coefficient.

\section{Results}

First, the crystallinity of base materials, SWCNTs and ZnO NWs, was determined by Raman spectroscopy and XRD, respectively. The nanocarbon component was of high quality, as revealed by the negligible intensity of the defect-induced band D (Figure 2a). It typically corresponds to lattice defects, functional groups on the surface of SWCNTs, and the presence of other $\mathrm{sp}^{3}$-rich types of carbon [31]. On the other hand, the G peak, indicative of the vibration of carbon atoms of $\mathrm{sp}^{2}$ hybridization, was narrow and of high intensity. The splitting of this feature into G- and G+ components [32] and the emergence of the Radial Breathing Mode (RBM) confirmed that the CNTs were indeed single-walled.

The ZnO NWs synthesized in-house also manifested a high degree of structural perfection (Figure $2 b$ ). The patterns were sharply defined and stayed in accordance with the features expected from a ZnO material. Zhou et al. [33] and Zappa et al. [25] previously reported matching XRD patterns for ZnO NWs. The obtained results mean that the NWs are exclusively made of high purity $\mathrm{ZnO}$ because of the absence of any other reflections.

Subsequently, the microstructure of SWCNTs, ZnO NWs, and their composites were studied by SEM (Figure 3). The starting SWCNT films were isotropic because filtration does not promote any degree of alignment, unless conducted under special conditions [34,35]. Bundles resulting from numerous van der Waals interactions between constituting CNTs can be clearly discerned. The amount of amorphous carbon, which typically contaminates CNT materials, was minimal.

Furthermore, the synthesized $\mathrm{ZnO}$ NWs were pure and of appreciable aspect ratio. In this case, as well, no obvious signs of impurities could be noted, resonating well with the results of the XRD analysis described above, which illustrated that the NW material is pristine. 
(a)
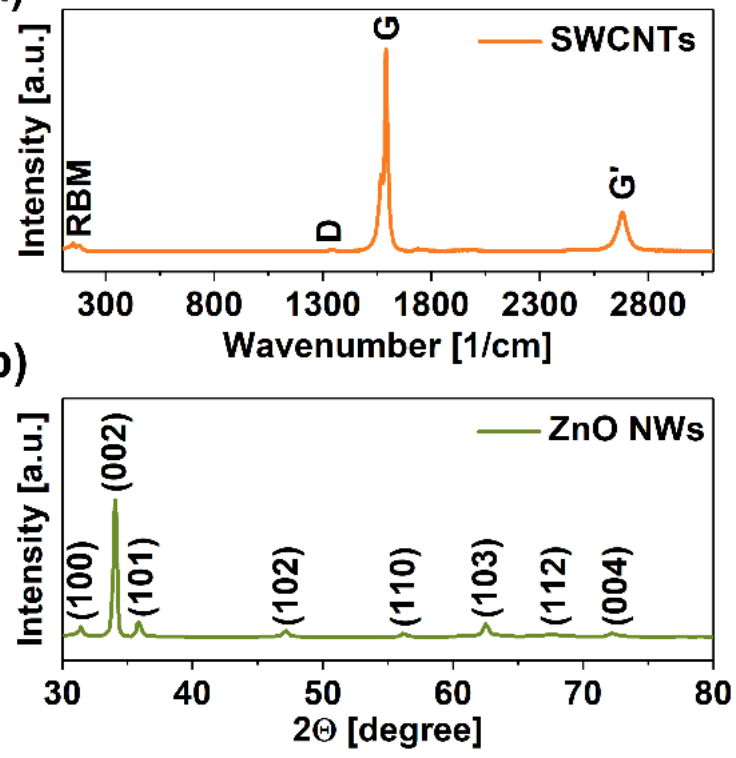

Figure 2. (a) Raman spectrum of SWCNTs and (b) XRD patterns of ZnO NWs used in the study.

Lastly, three types of composites were visualized, which differed in the amount of $\mathrm{ZnO}$ NWs introduced to the SWCNT films (5 $\mathrm{wt} \%, 10 \mathrm{wt} \%$, and $15 \mathrm{wt} \%$ with respect to SWCNTs). $\mathrm{ZnO}$ NWs were homogeneously distributed within the SWCNT matrix. In addition, the gradual increase in the amount of $\mathrm{ZnO} N W$ filler is evident in the provided micrographs. It is important to mention that both the components were properly integrated, which is confirmed by HR SEM (Figure S1). Individual SWCNTs and their bundles are wrapped around the $\mathrm{ZnO}$ NWs, which should ensure adequate charge propagation. Lastly, similar to the starting SWCNT film, the composites are also porous, judging by the considerable content of cavities filled with air under ambient conditions.

Having defined the composition of the materials, characterization of the electrical, thermal and thermoelectric properties was conducted. A thermogenerator requires at least one pair of p- and n-doped thermoelements to operate. As-made SWCNT films are of p-type character due to the $\mathrm{O}_{2}$ doping effect [36]. However, oxygen is not a promising dopant for this application, as it may easily desorb at high temperatures. Therefore, it is necessary to add a chemical compound stable at high temperature, with as low vapor pressure as possible, capable of extracting electrons from the $\mathrm{C}\left(\mathrm{sp}^{2}\right)$ lattice of SWCNTs at elevated temperature. It was discovered that 1,2,3-triazole is a suitable dopant as it is electron-poor and its boiling point exceeds $200{ }^{\circ} \mathrm{C}$ [37] (Figure 4). Importantly, the addition of this chemical compound increased the capabilities of the SWCNTs to transport charge. While the starting SWCNT films had an electrical conductivity of $211 \pm 11 \mathrm{~S} / \mathrm{cm}$, the value increased to $721 \pm 13 \mathrm{~S} / \mathrm{cm}$ upon doping with triazole, which was more than a threefold improvement. Simultaneously, the thermal conductivity of the SWCNT ensemble decreased from $3.81 \pm 0.14 \mathrm{~W} / \mathrm{m} \cdot \mathrm{K}$ to $2.19 \pm 0.06 \mathrm{~W} / \mathrm{m} \cdot \mathrm{K}$. It is beneficial, as minimization of thermal transport makes the temperature gradient necessary for the conversion of heat into electricity more stable. 


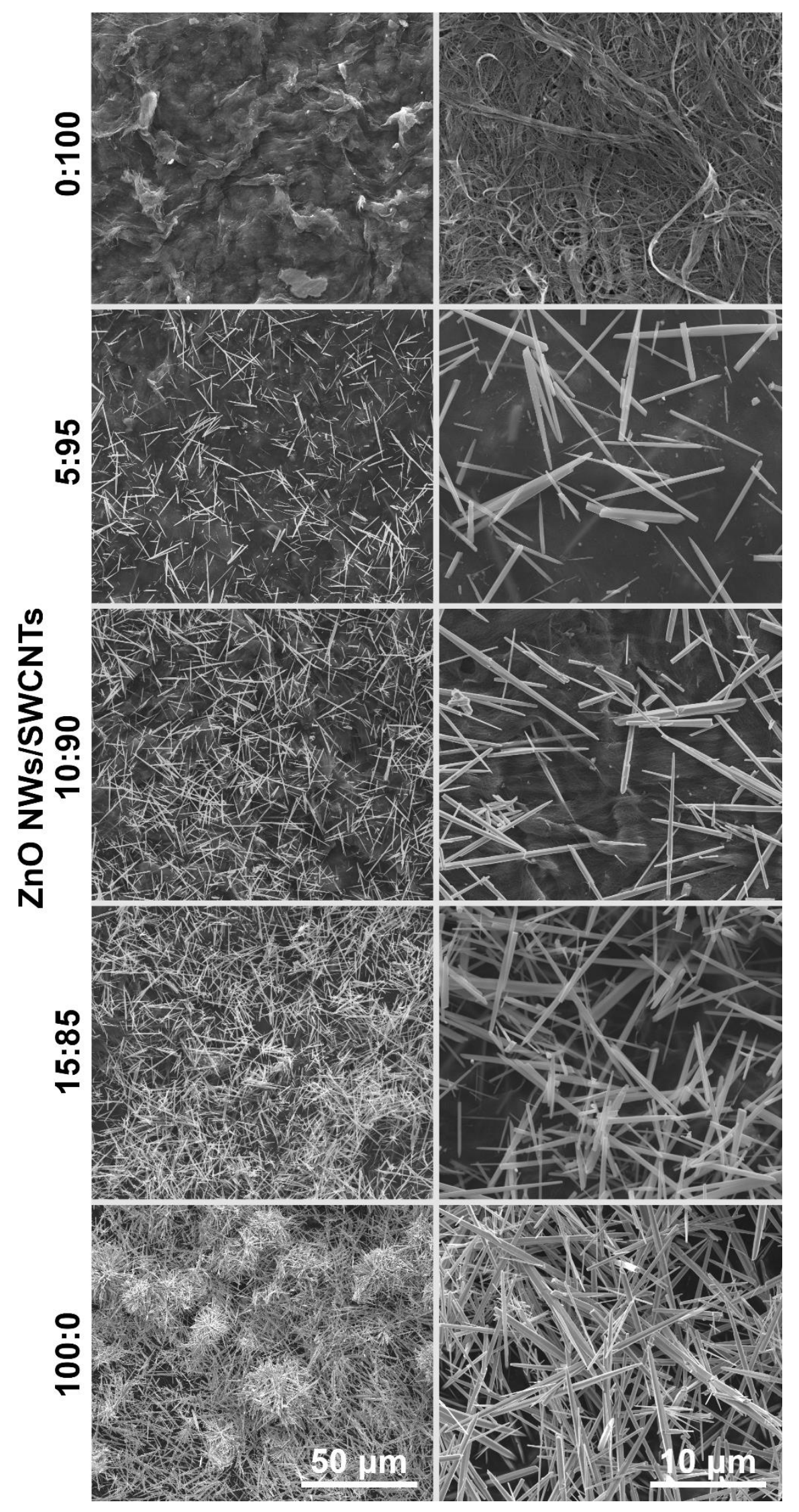

Figure 3. SEM micrographs of an SWCNT film, SWCNT films filled with ZnO NWs-5\%/10\%/15\% by weight, and $\mathrm{ZnO}$ NWs. 
(a)

Electrical conductivity $[\mathrm{S} / \mathrm{cm}]$

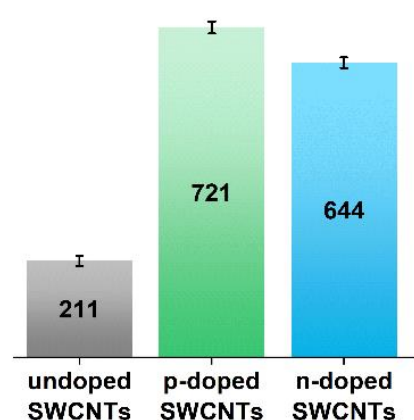

(c)

Seebeck coefficient $[\mu \mathrm{v} / \mathrm{K}]$

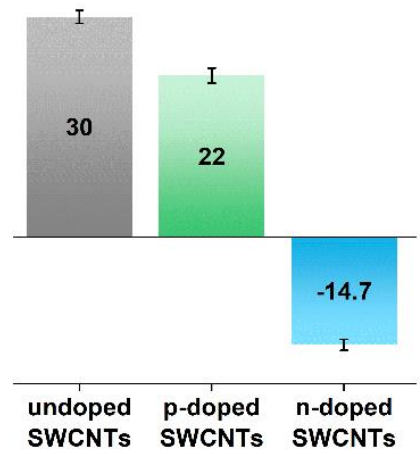

(e)

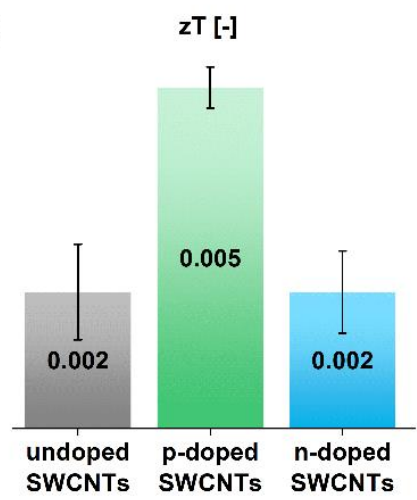

(b)

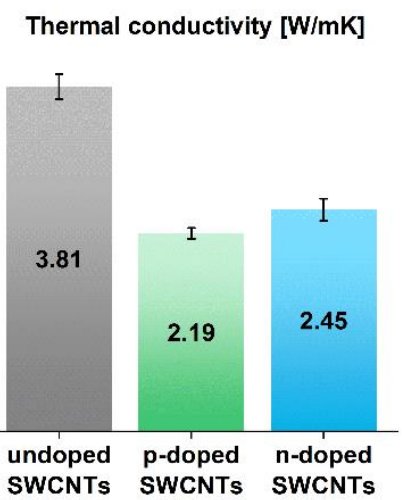

(d)

Power Factor $\left[\mu \mathrm{W} / \mathrm{mK}^{2}\right]$

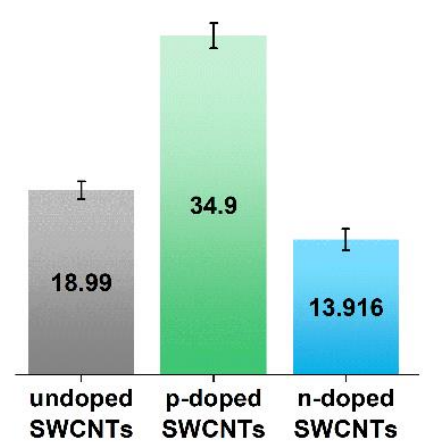

Figure 4. The impact of p-and n-doping of SWCNT films on the values of (a) electrical conductivity, (b) thermal conductivity, (c) Seebeck coefficient, (d) Power Factor, and (e) Figure of Merit.

Meanwhile, the Seebeck coefficient decreased from $30 \pm 0.90 \mu \mathrm{V} / \mathrm{K}$ to $22 \pm 1.01 \mu \mathrm{V} / \mathrm{K}$. Optimizing the parameters of materials for thermoelectrics is challenging as they are interdependent [15]. Thus, an increase in electrical conductivity is often accompanied by the deterioration of the Seebeck coefficient, which is what we observed. Measures that can quantify the net effect of these changes are Power Factor (disregarding the impact of thermal conductivity) and Figure of Merit zT (including this factor in the consideration). The results indicate that despite the decrease in the Seebeck coefficient, p-doping of SWCNTs almost doubled the value of the PF $\left(34.9 \pm 1.3 \mu \mathrm{W} / \mathrm{m} \cdot \mathrm{K}^{2}\right.$ vs. $\left.18.99 \pm 0.9 \mu \mathrm{W} / \mathrm{m} \cdot \mathrm{K}^{2}\right)$. Furthermore, because of the desired decrease in thermal conductivity, the beneficial effect of triazole was even more pronounced in the case of the Figure of Merit, which increased from 0.002 to 0.005 .

Finding an appropriate n-dopant for SWCNT-based thermogenerators is even more demanding, as it has to overcome the doping effect of oxygen present in the ambient. Moreover, it should be stable at high temperatures and, ideally, be unreactive toward the 
p-dopant, which may be emitted from the thermoelements, thereby decreasing the overall performance of the module. That is why commonly selected p-dopants, such as nitric [38] or sulfuric [39] acids, are not always applicable, if one considers the utilization of amines as n-dopants, as it may lead to an acid-base reaction. With this in mind, we decided to employ polyethyleneimine (PEI), which cannot react with triazole. Its addition caused a three-fold increase in electrical conductivity, with respect to the undoped SWCNT film, reaching $644 \pm 12 \mathrm{~S} / \mathrm{cm}$. Furthermore, the thermal conductivity of the n-doped SWCNT film was $2.45 \pm 0.12 \mathrm{~W} / \mathrm{m} \cdot \mathrm{K}$, which was similar to when the nanocarbon was doped with a triazole. However, even though the sign of the Seebeck coefficient was changed, which indicated successful n-doping, the magnitude of this parameter was unsatisfactory i.e., $-14.7 \pm 0.75 \mu \mathrm{V} / \mathrm{K}$. A high value of the Seebeck coefficient is necessary to reach appreciable thermoelectric performance, as in both Power Factor and the Figure of Merit, its effect is quadratic. This explains why, despite the increase in electrical conductivity, the Power Factor actually decreased to $13.92 \pm 1.10 \mu \mathrm{W} / \mathrm{m} \cdot \mathrm{K}^{2}$, compared with the starting material. In the case of the Figure of Merit, this problem was somewhat alleviated by the favorable decrease in the value of thermal conductivity. Nonetheless, the Figure of Merit remained at precisely the same level i.e., 0.002. This displeasing outcome motivated us to search for another material, the addition of which would lead to a higher n-doping performance.

Because of the previously reported n-type behavior of ZnO NWs [40,41], ZnO NWs were included in the n-doped SWCNT thermoelements (Figure 5). The addition was shown to improve the electrical conductivity of the network, up to the content of $10 \mathrm{wt} \%$ $(777 \pm 12 \mathrm{~S} / \mathrm{cm})$, after which it decreased with $15 \mathrm{wt} \% \mathrm{ZnO}$ NWs (512 $\pm 10 \mathrm{~S} / \mathrm{cm})$. Moreover, a tangible decrease in thermal conductivity was also observed. This parameter was beneficially reduced by a factor of three, eventually reaching $0.83 \mathrm{~W} / \mathrm{m} \cdot \mathrm{K}$. Apparently, the presence of ZnO NWs in the structure disturbs the heat transport between the individual SWCNTs.

The biggest benefit of interfacing SWCNTs with ZnO NWs was the increase in the absolute values of the Seebeck coefficient. A gradual improvement in the thermopower was observed with the increasing $\mathrm{ZnO}$ NW amount. At $15 \mathrm{wt} \%$ of $\mathrm{ZnO}$ NWs, the Seebeck coefficient reached values as low as $-24 \pm 0.93 \mu \mathrm{V} / \mathrm{K}$. Overall, when all three parameters (electrical conductivity, thermal conductivity, and Seebeck coefficient) are considered, the best net effect was obtained in the case of $10 \mathrm{wt} \% \mathrm{ZnO} \mathrm{NWs}$ in the material. The Power Factor increased from $18.99 \pm 0.9 \mu \mathrm{W} / \mathrm{m} \cdot \mathrm{K}^{2}$ to $42.91 \pm 2.7 \mu \mathrm{W} / \mathrm{m} \cdot \mathrm{K}^{2}$, which is an improvement of over $100 \%$. Although the sample containing $15 \mathrm{wt} \% \mathrm{ZnO}$ NWs exhibited the highest absolute value of the Seebeck coefficient, its influence was minimized by lower electrical conductivity with respect to the starting material. Lastly, because of the beneficial decrease in thermal conductivity for $\mathrm{ZnO}$ NW-enriched n-doped SWCNT thermoelements, the advantage coming from the implementation of $\mathrm{ZnO} N W s$ is even more evident, when looking from the Figure of Merit perspective. In this case, one can see an eight-fold improvement, as the value of zT increased from 0.002 to 0.016 .

Finally, the utility of the developed SWCNT-based thermoelements (n-type), containing PEI and $\mathrm{ZnO}$ NWs, as well as (p-type) employing triazole was demonstrated. Thermoelectric modules were constructed from 5, 10, and $25 n-p$ pairs made from the materials mentioned above (Figure 6). Then, the modules were subjected to various temperature gradients (Figure 6a), and the Open Circuit Voltage was measured (Figure 6b). The amount of electrical energy generated from waste heat was proportional to the magnitude of the temperature difference or the number of $n-p$ pairs. Electric potential as large as $102 \pm 7.14 \mathrm{mV}$ was established for the biggest module at $95^{\circ} \mathrm{C}$ difference. 
(a)

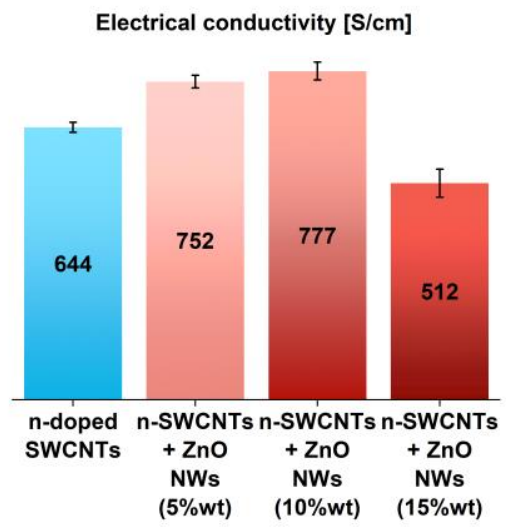

(c)

Seebeck coefficient $[\mu \mathrm{v} / \mathrm{K}]$
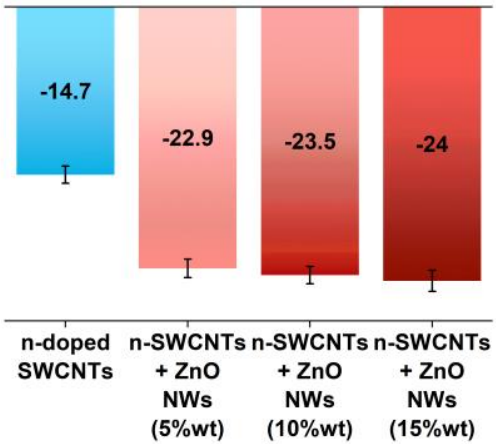

(e)

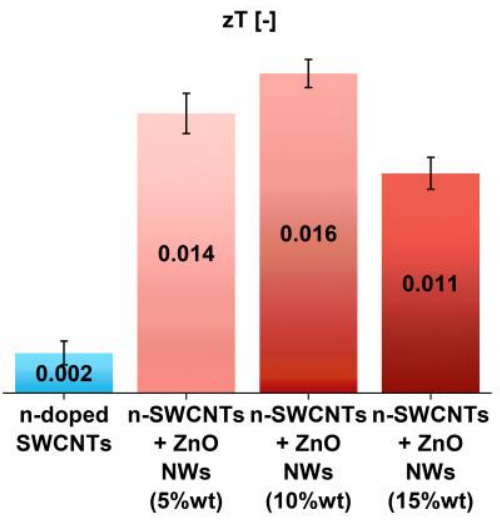

(b) Thermal conductivity $[\mathrm{W} / \mathrm{mK}]$

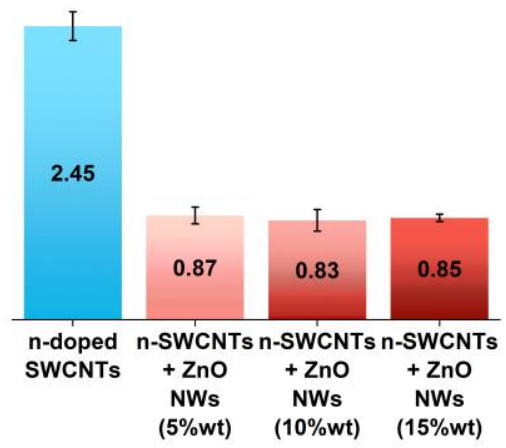

(d)

Power Factor $\left[\mu \mathrm{W} / \mathrm{mK}^{2}\right]$

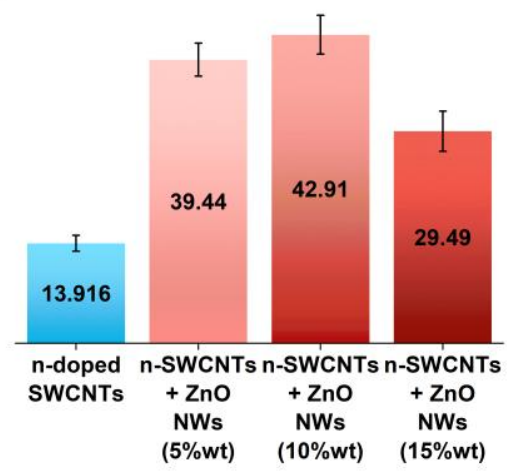

Figure 5. The influence of the incorporation of $\mathrm{ZnO} N W s$ ( $5 \mathrm{wt} \%, 10 \mathrm{wt} \%$, and $15 \mathrm{wt} \%$ with respect to SWCNTs) into n-doped SWCNT films on the values of (a) electrical conductivity, (b) thermal conductivity, (c) Seebeck coefficient, (d) Power Factor, and (e) Figure of Merit.

The results also suggest that the proposed solution is readily scalable (Figure 6c). Average Seebeck coefficients (determined from the slopes of the linear fits shown in Figure 6b) show virtually no changes, regardless of the number of employed n-p pairs. Consequently, it should be possible to obtain much more thermopower by creating modules containing many more n-p pairs. Alternatively, several modules could be connected in parallel or in series to increase the magnitude of the produced current or electric potential, respectively. 
(a)

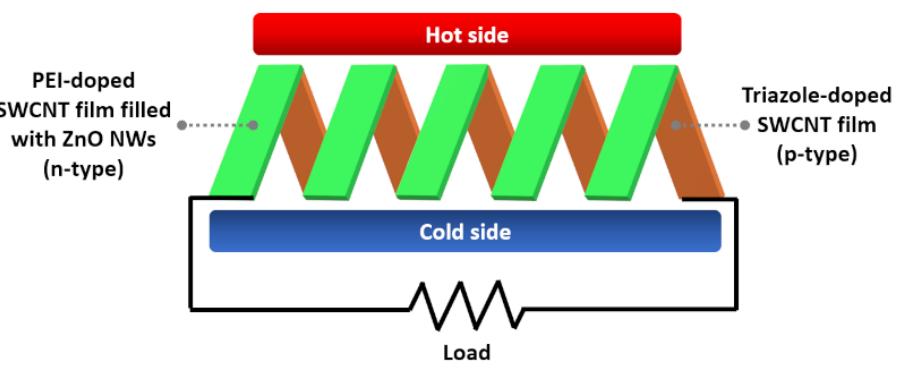

(b)

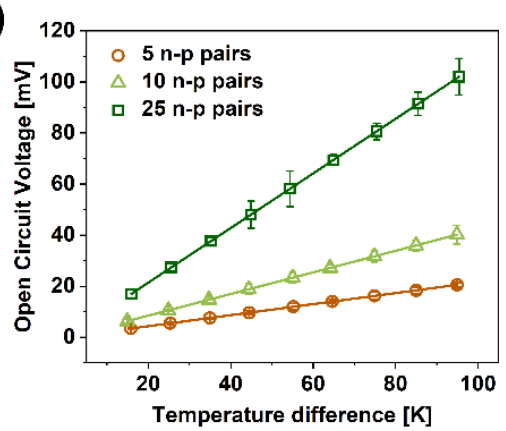

(c)

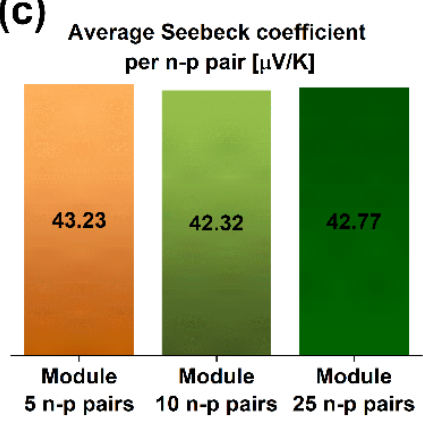

Figure 6. (a) Schematic representation of the evaluated module made from SWCNTs, ZnO NWs, and $\mathrm{PEI} /$ triazole as $\mathrm{n}$ - and p-dopants, respectively, (b) the magnitude of generated Open Circuit Voltage as a function of the temperature difference and the number of employed n-p pairs, and (c) average Seebeck coefficient per $n-p$ pair determined from the slopes of the curves presented in panel (b).

\section{Conclusions}

The study illustrates the versatile nature of SWCNTs, the properties of which can be readily adapted for an envisioned application, by mixing with appropriate chemical compounds or other components. Due to their amphoteric character, it was possible to obtain both $\mathrm{p}$ - and n-doped thermoelements by using triazole and polyethyleneimine, respectively. While the performance of the former hybrid was acceptable, it was necessary to include additional filler, in the case of the latter, to reach appreciable characteristics. Through the application of $\mathrm{ZnO}$ NWs, it was possible to increase the values of Power Factor and the Figure of Merit several times. A fully functioning prototype, capable of transforming waste heat into electricity, made from such elements, was made and tested. It was shown that such a module can generate a considerable amount of thermopower. Importantly, its operational parameters were found to be scalable, so it should be possible to increase its size to generate even more electrical energy.

Because of numerous types of nanomaterials, which fully cover the spectrum of potential properties, the number of possible combinations between them is virtually limitless. The birth of other promising types of nanomaterials, in recent years, such as transition metal dichalcogenides or MXenes, provides plenty of opportunities for further explorations into how the hybridization of several types of materials and nanomaterials may enable the tailoring of properties for particular applications.

Supplementary Materials: The following supporting information can be downloaded at: https: / / www.mdpi.com/article/10.3390/ma15051924/s1, Figure S1: SEM micrograph of an SWCNT film filled with $15 \mathrm{wt} \% \mathrm{ZnO} \mathrm{NWs}$ by weight.

Author Contributions: Conceptualization, D.J.; data curation, D.J.; formal analysis, P.T., T.W., M.S., M.L. and D.J.; funding acquisition, M.L. and D.J.; investigation, P.T., T.W., M.S. and D.J.; methodology, P.T. and D.J.; project administration, D.J.; resources, M.L. and D.J.; supervision, D.J.; validation, D.J.; visualization, D.J.; writing-original draft, P.T., T.W., M.S., M.L. and D.J. All authors have read and agreed to the published version of the manuscript. 
Funding: P.T., T.W. and D.J. would like to thank the National Centre for Research and Development, Poland (under the Leader program, Grant agreement LIDER/0001/L-8/16/NCBR/2017), for financial support of the research, and the National Agency for Academic Exchange of Poland (under the Academic International Partnerships program, grant agreement PPI/APM/2018/1/0004) for sponsoring an internship at Aalto University, Finland, which enabled the execution of a part of this study. M.L. and M.S. acknowledge the Academy of Finland's RawMatTERS Finland Infrastructure (RAMI) based at Aalto University.

Institutional Review Board Statement: Not applicable.

Informed Consent Statement: Not applicable.

Data Availability Statement: Data from this study are available from the corresponding author upon a reasonable request.

Acknowledgments: We acknowledge the support from OtaNano-Aalto University in conducting this research.

Conflicts of Interest: The authors declare no conflict of interest. The funders had no role in the design of the study; in the collection, analyses, or interpretation of data; in the writing of the manuscript, or in the decision to publish the results.

\section{References}

1. Hamakawa, Y. Solar PV Energy Conversion and the 21st Century's Civilization. Sol. Energy Mater. Sol. Cells 2002, 74, 13-23. [CrossRef]

2. Pereirinha, P.G.; González, M.; Carrilero, I.; Anseán, D.; Alonso, J.; Viera, J.C. Main Trends and Challenges in Road Transportation Electrification. Transp. Res. Procedia 2018, 33, 235-242. [CrossRef]

3. Grenier, A.; Page, S. The Impact of Electrified Transport on Local Grid Infrastructure: A Comparison between Electric Cars and Light Rail. Energy Policy 2012, 49, 355-364. [CrossRef]

4. Filip, M.E.; Csaba, G.; Lelea, D. Comparative Analysis of Heat Recovery Methods from Internal Combustion Engines. IOP Conf. Ser. Mater. Sci. Eng. 2019, 477, 012011. [CrossRef]

5. Monthioux, M.; Kuznetsov, V.L. Who Should Be given the Credit for the Discovery of Carbon Nanotubes? Carbon 2006, 44, 1621-1623. [CrossRef]

6. Lekawa-Raus, A.; Patmore, J.; Kurzepa, L.; Bulmer, J.; Koziol, K. Electrical Properties of Carbon Nanotube Based Fibers and Their Future Use in Electrical Wiring. Adv. Funct. Mater. 2014, 24, 3661-3682. [CrossRef]

7. Bandaru, P.R. Electrical Properties and Applications of Carbon Nanotube Structures. J. Nanosci. Nanotechnol. 2007, 7, 1239-1267. [CrossRef] [PubMed]

8. Kumanek, B.; Janas, D. Thermal Conductivity of Carbon Nanotube Networks: A Review. J. Mater. Sci. 2019, 54, 7397-7427. [CrossRef]

9. Han, Z.; Fina, A. Thermal Conductivity of Carbon Nanotubes and Their Polymer Nanocomposites: A Review. Prog. Polym. Sci. 2011, 36, 914-944. [CrossRef]

10. Bazbouz, M.B.; Aziz, A.; Copic, D.; De Volder, M.; Welland, M.E. Fabrication of High Specific Electrical Conductivity and High Ampacity Carbon Nanotube/Copper Composite Wires. Adv. Electron. Mater. 2021, 7, 2001213. [CrossRef]

11. Zou, J.; Liu, D.; Zhao, J.; Hou, L.; Liu, T.; Zhang, X.; Zhao, Y.; Zhu, Y.T.; Li, Q. Ni Nanobuffer Layer Provides Light-Weight CNT/Cu Fibers with Superior Robustness, Conductivity, and Ampacity. ACS Appl. Mater. Interfaces 2018, 10, 8197-8204. [CrossRef] [PubMed]

12. Subramaniam, C.; Yasuda, Y.; Takeya, S.; Ata, S.; Nishizawa, A.; Futaba, D.; Yamada, T.; Hata, K. Carbon Nanotube-Copper Exhibiting Metal-like Thermal Conductivity and Silicon-like Thermal Expansion for Efficient Cooling of Electronics. Nanoscale 2014, 6, 2669-2674. [CrossRef] [PubMed]

13. Nakai, Y.; Honda, K.; Yanagi, K.; Kataura, H.; Kato, T.; Yamamoto, T.; Maniwa, Y. Giant Seebeck Coefficient in Semiconducting Single-Wall Carbon Nanotube Film. Appl. Phys. Express 2014, 7, 025103. [CrossRef]

14. Komatsu, N.; Ichinose, Y.; Dewey, O.S.; Taylor, L.W.; Trafford, M.A.; Yomogida, Y.; Wehmeyer, G.; Pasquali, M.; Yanagi, K.; Kono, J. Macroscopic Weavable Fibers of Carbon Nanotubes with Giant Thermoelectric Power Factor. Nat. Commun. 2021, 12, 4931. [CrossRef]

15. Blackburn, J.L.; Ferguson, A.J.; Cho, C.; Grunlan, J.C. Carbon-Nanotube-Based Thermoelectric Materials and Devices. Adv. Mater. 2018, 30, 1704386. [CrossRef]

16. Shi, X.; Sun, C.; Bu, Z.; Zhang, X.; Wu, Y.; Lin, S.; Li, W.; Faghaninia, A.; Jain, A.; Pei, Y. Revelation of Inherently High Mobility Enables Mg3Sb2 as a Sustainable Alternative to N-Bi2Te3 Thermoelectrics. Adv. Sci. 2019, 6, 1802286. [CrossRef]

17. Li, W.; Zheng, L.; Ge, B.; Lin, S.; Zhang, X.; Chen, Z.; Chang, Y.; Pei, Y. Promoting SnTe as an Eco-Friendly Solution for p-PbTe Thermoelectric via Band Convergence and Interstitial Defects. Adv. Mater. 2017, 29, 1605887. [CrossRef] 
18. Yan, X.; Liu, W.; Wang, H.; Chen, S.; Shiomi, J.; Esfarjani, K.; Wang, H.; Wang, D.; Chen, G.; Ren, Z. Stronger Phonon Scattering by Larger Differences in Atomic Mass and Size in P-Type Half-Heuslers Hf1-xTixCoSb0.8Sn0.2. Energy Environ. Sci. 2012, 5 , 7543-7548. [CrossRef]

19. Janas, D. From Bio to Nano: A Review of Sustainable Methods of Synthesis of Carbon Nanotubes. Sustainability 2020, $12,4115$. [CrossRef]

20. Balasubramanian, K.; Burghard, M. Chemically Functionalized Carbon Nanotubes. Small 2005, 1, 180-192. [CrossRef]

21. Miners, S.A.; Rance, G.A.; Khlobystov, A.N. Chemical Reactions Confined within Carbon Nanotubes. Chem. Soc. Rev. 2016, 45, 4727-4746. [CrossRef] [PubMed]

22. Nonoguchi, Y.; Ohashi, K.; Kanazawa, R.; Ashiba, K.; Hata, K.; Nakagawa, T.; Adachi, C.; Tanase, T.; Kawai, T. Systematic Conversion of Single Walled Carbon Nanotubes into N-Type Thermoelectric Materials by Molecular Dopants. Sci. Rep. 2013, 3, 3344. [CrossRef] [PubMed]

23. Bulmer, J.S.; Lekawa-Raus, A.; Rickel, D.G.; Balakirev, F.F.; Koziol, K.K. Extreme Magneto-Transport of Bulk Carbon Nanotubes in Sorted Electronic Concentrations and Aligned High Performance Fiber. Sci. Rep. 2017, 7, 12193. [CrossRef]

24. Kang, D.; Park, N.; Ko, J.; Bae, E.; Park, W. Oxygen-Induced p-Type Doping of a Long Individual Single-Walled Carbon Nanotube. Nanotechnology 2005, 16, 1048-1052. [CrossRef]

25. Zappa, D.; Dalola, S.; Faglia, G.; Comini, E.; Ferroni, M.; Soldano, C.; Ferrari, V.; Sberveglieri, G. Integration of ZnO and CuO Nanowires into a Thermoelectric Module. Beilstein J. Nanotechnol. 2014, 5, 927-936. [CrossRef]

26. Rdest, M.; Janas, D. Effective Doping of Single-Walled Carbon Nanotubes with Polyethyleneimine. Materials 2021, 14, 65. [CrossRef]

27. Liu, P.; Fan, Z.; Mikhalchan, A.; Tran, T.Q.; Jewell, D.; Duong, H.M.; Marconnet, A.M. Continuous Carbon Nanotube-Based Fibers and Films for Applications Requiring Enhanced Heat Dissipation. ACS Appl. Mater. Interfaces 2016, 8, 17461-17471. [CrossRef] [PubMed]

28. Zhang, L.; Zhang, G.; Liu, C.; Fan, S. High-Density Carbon Nanotube Buckypapers with Superior Transport and Mechanical Properties. Nano Lett. 2012, 12, 4848-4852. [CrossRef]

29. Wang, D.; Song, P.; Liu, C.; Wu, W.; Fan, S. Highly Oriented Carbon Nanotube Papers Made of Aligned Carbon Nanotubes. Nanotechnology 2008, 19, 075609. [CrossRef]

30. Kumanek, B.; Przypis, Ł.; Wróbel, P.S.; Krzywiecki, M.; Walczak, K.Z.; Janas, D. Convenient but Powerful Method to Dope Single-Walled Carbon Nanotube Films with Iodonium Salts. Appl. Nanosci. 2020, 10, 529-539. [CrossRef]

31. Dresselhaus, M.S.; Dresselhaus, G.; Jorio, A.; Souza Filho, A.G.; Saito, R. Raman Spectroscopy on Isolated Single Wall Carbon Nanotubes. Carbon 2002, 40, 2043-2061. [CrossRef]

32. Costa, S.; Borowiak-Palen, E.; Kruszynska, M.; Bachmatiuk, A.; Kalenczuk, R. Characterization of Carbon Nanotubes by Raman Spectroscopy. Mater. Sci.-Pol. 2008, 26, 433-441.

33. Zhou, Q.; Wen, J.Z.; Zhao, P.; Anderson, W.A. Synthesis of Vertically-Aligned Zinc Oxide Nanowires and Their Application as a Photocatalyst. Nanomaterials 2017, 7, 9. [CrossRef] [PubMed]

34. Rust, C.; Li, H.; Gordeev, G.; Spari, M.; Guttmann, M.; Jin, Q.; Reich, S.; Flavel, B.S. Global Alignment of Carbon Nanotubes via High Precision Microfluidic Dead-End Filtration. Adv. Funct. Mater. 2021, 32, 2107411. [CrossRef]

35. Komatsu, N.; Nakamura, M.; Ghosh, S.; Kim, D.; Chen, H.; Katagiri, A.; Yomogida, Y.; Gao, W.; Yanagi, K.; Kono, J. GrooveAssisted Global Spontaneous Alignment of Carbon Nanotubes in Vacuum Filtration. Nano Lett. 2020, 20, 2332-2338. [CrossRef] [PubMed]

36. Lekawa-Raus, A.; Kurzepa, L.; Kozlowski, G.; Hopkins, S.C.; Wozniak, M.; Lukawski, D.; Glowacki, B.A.; Koziol, K.K. Influence of Atmospheric Water Vapour on Electrical Performance of Carbon Nanotube Fibres. Carbon 2015, 87, 18-28. [CrossRef]

37. Nizam Uddin, M.; Siddiquey, I.A.; Jahurul Islam, M.; Fouad, O.A.; Nagano, M. 1H-1,2,3-Triazole, a Promising Precursor for Chemical Vapor Deposition of Hydrogenated Carbon Nitride. J. Cryst. Growth 2009, 311, 3528-3532. [CrossRef]

38. Hayashi, D.; Nakai, Y.; Kyakuno, H.; Yamamoto, T.; Miyata, Y.; Yanagi, K.; Maniwa, Y. Improvement of Thermoelectric Performance of Single-Wall Carbon Nanotubes by Heavy Doping: Effect of One-Dimensional Band Multiplicity. Appl. Phys. Express 2016, 9, 125103. [CrossRef]

39. Zhou, W.; Vavro, J.; Nemes, N.M.; Fischer, J.E.; Borondics, F.; Kamaras, K.; Tanner, D. Charge Transfer and Fermi Level Shift in P-Doped Single-Walled Carbon Nanotubes. Phys. Rev. B 2005, 71, 205423. [CrossRef]

40. Jantrasee, S.; Moontragoon, P.; Pinitsoontorn, S. Thermoelectric Properties of Al-Doped ZnO: Experiment and Simulation. J. Semicond. 2016, 37, 092002. [CrossRef]

41. Ishibe, T.; Tomeda, A.; Watanabe, K.; Kamakura, Y.; Mori, N.; Naruse, N.; Mera, Y.; Yamashita, Y.; Nakamura, Y. Methodology of Thermoelectric Power Factor Enhancement by Controlling Nanowire Interface. ACS Appl. Mater. Interfaces 2018, 10, 37709-37716. [CrossRef] [PubMed] 